\title{
Get prepared: Discourse for the privileged?
}

\author{
Denise Blake $^{\mathrm{a}, *}$, Jay Marlowe ${ }^{\mathrm{b}}$, David Johnston ${ }^{\mathrm{a}}$ \\ a Joint Centre for Disaster Research, School of Psychology, Massey University, Wellington 6140, New Zealand \\ b School of Counselling, Human Services and Social Work, University of Auckland, Private Bag 92-601, Symonds Street, Auckland 1150, New Zealand
}

\section{A R T I C L E I N F O}

\section{Keywords:}

Disasters

Disadvantage

Poverty

Ontological security

Structural violence

Vulnerable

\begin{abstract}
A B S T R A C T
Being prepared for a disaster is an important strategy for reducing physical, social, psychological and cultural harm. Preparedness practices mitigate the immediate impacts of a disaster while also enabling people to respond to and cope with any ongoing consequences. However, not all people have the ability to prepare. This paper queries how preparedness discourses impact on people without financial means, capacity or support to prepare. The work situates preparedness within a neoliberal system that is preoccupied with risk management as an economic cost reducing exercise. It highlights that without the ability to feel safe and achieve ontological security in a disaster, people can experience instability and mental health is compromised. It questions disaster preparedness texts that produce a form of structural violence, preventing the ability to have needs meet, while privileging agency to some and denying it to others. Government documents and preparedness websites from Aotearoa/New Zealand are outlined to highlight the frequently ignored preparedness needs of vulnerable groups. The role of research in preparedness activities is also discussed. People working in the emergency management space should contest the socio-political conditions that produce increased risk for disadvantaged groups.
\end{abstract}

\section{Introduction}

Since the Aotearoa/New Zealand Canterbury earthquakes sequence, specifically the February 2011 magnitude 6.3 quake that caused the deaths of 185 people [31,40], citizens of Aotearoa/New Zealand are directed by emergency management institutions, such as the Ministry of Civil Defence and Emergency Management, to prepare should another disaster occur. The 2016 magnitude 7.8 Kaikoura earthquake, where two people lost their lives, has further initiated a flurry of preparedness directives reminding people that they have a greater chance of recovery and survival when they prepare. With the ongoing public debates about climate change increasing the risks of natural hazards [51] and media representations of global disasters including natural hazards, such as hurricanes and storms, and human induced disasters like terrorism and disease we are reminded that we must prepare for any unexpected events [16]. Preparedness discourses encourage people to be self-sufficient and resilient in the response and recovery phases of a disaster [3]. Being prepared involves having necessary survival items, such as adequate supplies of water, food, torches, first-aid kits, radios, appropriate clothing and footwear. It also involves having a robust emergency management plan, securing furniture and other items around the home, and property insurance [5]. As argued by Baker and Cormier [3], preparedness requires the ability to have sufficient personal, social and financial effects.

Being prepared for a disaster however, is not possible for people who are unable to prepare because of financial constraints, limited social connections, capacity and support. Often positioned in emergency management as 'vulnerable', minority groups and marginalised people, such as the poor, are disadvantaged in preparedness practices because they lack the necessary resources to prepare. Without adequate water, food, housing, transport and healthcare for day-to-day existence it is difficult to have the ability to store additional emergency survival items necessary to preparedness [3].

This work does not refute that it is important to prepare, it argues that preparedness should be situated within a socio-political context that privileges agency to some while denying it to others. This paper discusses the unintended consequences of disaster preparedness discourse and considers the way in which socio-political influences intersect with hazards and preparedness practices. We begin by contextualising a risk society within neoliberal systems and discuss the impact of preparedness on ontological security, a process that enables people to experience an enduring identity and a sense of stability. Vulnerability and structural violence, the way in which institutions govern people's agency [18], are also explored. We then identify some preparedness discourses in Aotearoa/New Zealand texts, exploring how these texts overlook preparedness needs for disadvantaged groups. We

\footnotetext{
* Corresponding author.

E-mail address: d.blake@massey.ac.nz (D. Blake).
} 
argue for the importance of critical research that contests a social political agenda and supports the needs of disadvantaged groups to be able to prepare.

\section{Risk society}

Preparedness directives are embedded within societies that are preoccupied with risk. Risk is understood as the social concern with uncertainty, which governs people's thoughts, feelings and behaviours $[12,25,50]$. As argued by Beck [4], risk is "experienced as omni-present" (p. 331) with modern society attempting to analyse, prevent and manage risk. Risks are constructed through social advancements and can be the side effects of technological developments and consumer capitalism. Industrialised and urbanised societies, alongside globalisation and population growth have meant that when natural hazards interact with modernity, disasters strike and people are hurt. For instance, flooding risk occurs when residential, industrial and infrastructural buildings are erected on floodplains; earthquake risk is created when commercial structures are not built to withstand seismic activity $[11,50]$. According to Lübken [27] the effects of climate change represent how disasters are often socially and politically determined. Within the climate change context, disasters are viewed as a new, uncontrollable environmental condition that is inevitable, unseen and central to the way a society functions.

Risk and preparedness are often underpinned by neoliberal policies that constrain public expenditure on education, health and social initiatives. Based on the assumption that all people have agency, neoliberalism dismantles governmental and welfare support placing responsibility for risk and survival directly on the individual. The capitalist, market-driven economies of western neoliberal systems privilege consumerism, innovation and freedom of choice where notions of self-responsibility, self-determination and self-efficacy feed cultural discourses of individualism making people accountable [8]. These dynamics are evident with preparedness and emergency safety plans. In particular, Farmer [14] wrote that a neoliberal agenda excluded the powerless, disadvantaged and poor. Macroeconomic impacts have greater consequences for vulnerable groups living with high poverty, unemployment and exclusion from basic services. This can mean that existing socio-economic vulnerability is further perpetuated where countries can incur more debt and be unable to rebuild, for example. Communities with greater economic stability are more able to mobilise resources prior to a disaster event and in the disaster recovery phase $[32,41]$.

In relation, notions of risk assessment and vulnerability can be viewed as a dynamic process that involves layers that can be added or removed, rather than a fixed state or label [28]. Whilst an awareness of vulnerability is important, this work recognises that people or communities who are vulnerable also have the ability to anticipate, cope, respond, adapt and recover from the consequences of a disaster [59]. Any vulnerability is contingent on relationships between people and contexts. However, governments, institutions and those involved in emergency management recognise that specific groups can be inherently vulnerable to disaster risk including women, children, older people, prisoners, ethnic minorities, refugees, people with literacy and language barriers, people with disability, and those living in lower socio-economic conditions $[3,23,59]$.

The notion of risk has implications for our sense of ontological security, the uncertainty and worry about no longer waking up to a world that is known [25]. Giddens [19] defines ontological security as the sense of continuity that underlies our experience of identity and the belief that there is consistency in our social context and geographical space. When we have ontological security we feel safe because it provides a protective mechanism against overwhelming feelings of anxiety if we try to make sense of the meaning of life and existence. With ontological security we have a framework to bracket reality and a buffer to enrich our psychological health. Experiencing ontological security requires the ability to have trust in the everyday functioning and reliability of people, places and objects at an unconscious and practically conscious level $[19,25]$. Without ontological security we experience the world as fragmented where assumed meanings, structures, relationships and support systems are not stable. Without the resources to feel safe and secure, ontological security is shaken and existential anxiety can manifest. To understand the process of ontological security during a disaster, Hawkins and Maurer [20] explored the impact of Hurricane Katrina on experiences of ontological security. Forty participants described disruptions to experiences of safety and trust because of the breakdown in individual, community and structural functioning brought about by the storm causing physical, psychological and geographical displacement. Jaeger et al. [25] also found that when unable to rebuild one's home, life or community it disrupted experiences of ontological safety, increased vulnerability to anxiety and, overall, poorer mental health. The human desire for ontological security produces social actions that aim to control people and environments. It can promote practices of resiliency such as preparedness, and within a risk focused society, being prepared helps to decrease experiences of fear and insecurity. However, when people are economically disadvantaged ontological security is problematic because of increased vulnerability to hazards and emergencies.

\section{Poverty and preparedness}

People who are labelled as vulnerable, especially the poor, can find it challenging to reconstruct their lives after a disaster strikes. They often live in high-risk areas that expose them to greater disaster related risk and have substandard housing that cannot withstand disaster events, such as an earthquake. In relation to mobility, maintaining cars is economically problematic and transport issues restrict evacuation $[3,9,38,59]$. Without insurance, people cannot replace household goods such as bedding and floor coverings. There is no money to replenish clothing, televisions or toys. With little formal education or few job prospects, geographical movement is limited or impossible if house bonds and rent payments cannot be met. Zakour and Gillespie [60] write about the importance of adequate household and community wealth in the recovery phase following a disaster. Without resources, communities can falter, not adapt to changes and struggle to resiliently 'bounce back' from a traumatic event.

Further aggravating recovery is a lack of social capital. Aldrich [2] found that social capital, the networks and resources that occur through social connection, can aid communities to recover despite economic disadvantages or a lack of governmental or agency support. However, without social bonding or social resources, communities are less able to regroup and rebuild. Increased community discrimination and exclusion are also evident when social benefits are localised by communities high in social capital. Within these contexts, the experience of ontological security can be fragmented.

In 2015, in Aotearoa/New Zealand, an estimated $28 \%$ of children 17 years and under experienced income poverty (below $60 \%$ of the median income after adjusting for housing costs), with three out of five children (0-11 years) living in persistent poverty (average income over seven years being below the average low income poverty line) $[47,48]$. These children endured un-insulated, cold and overcrowded homes, went hungry, experienced third world diseases (such as rheumatic fever) and were unable to attend extracurricular activities or additional tuition for school [6]. Poverty, when enduring and persistent, is associated with a wide range of negative health, education, employment, justice and social outcomes $[6,41,46]$. Poverty affects people throughout their lives, causing increased welfare needs, reliance on state support, higher costs of healthcare, criminal offending and lower social productivity $[38,44]$.

That poverty and inequality continues to grow in Aotearoa/New Zealand, especially after the recent global financial crisis, seems pertinent in the emergency management space. Without financial or social means, people are inevitably reliant on state-based institutions to 
function and survive. Yet, state support is inadequate and continues to recede due to punitive welfare reforms within Aotearoa/New Zealand's neoliberal climate. Where basic survival needs are neglected or denied, victim-blaming practices (often pathologised) produce and reproduce people as deficient within poverty-stricken contexts where they are unable to thrive [20]. People can be excluded from being able to prepare for a disaster although they are subjected to, and constructed by, the same discourses of risk as everyone else. Disaster preparedness campaigns are circulated (unevenly) through television, newspapers, radios, social media and word of mouth whereby people's social capital resources and everyday life experiences dictate the accessibility and appropriateness of such messaging. When faced with media campaigns about disaster risks and preparedness it can be distressing and threaten experiences of ontological security.

For instance, in 2013, the Aotearoa/New Zealand Earthquake Commission removed a series of television adverts warning people to be prepared for earthquakes because mental health groups were concerned that it would re-traumatise people from Canterbury, according to the Christchurch Press [13]. The same concerns can be extended to people without the capacity to prepare. For example, we need to consider the impact of preparedness advertising on children who are aware that their families do not have the means to secure furniture, stockpile food or other items. Further, we need to consider the process of ontological insecurity for parents who are unable to provide for their children's daily needs, let alone store additional food or purchase other goods for disaster preparedness.

Without the means to prepare, while there are social imperatives to prepare, structural violence is inflicted. Structural violence, a broad term that highlights social inequality and injustice, represents the impact of institutions on people when they prohibit or limit people's agency to act. Violence in this sense is structural, and needs to be understood as any process that influences somatic and mental experiences that lessen people's potential abilities and forms of resilience $[17,54]$. As argued by Ho [21], structural violence occurs within abusive and unequal social power relationships and is intensified within neoliberal systems. Structural violence is characterised as the way in which social processes and governing or state structures disadvantage particular people; it is imposed in everyday life through socio-economic and institutional systems that use punitive policies and austerity measures to control its citizens. Hodgetts et al. [22] provided an example of punitive welfare practices in an Aotearoa/New Zealand welfare agency. The effects of judgemental and uncompassionate interactions with the Work and Income New Zealand staff produced anxiety, shame and fear in clients who were requesting support for basic human needs, like dental care and accommodation. The research emphasised that large public service institutions can perform violence against those it claims to serve, by the way in which they talk, act and treat their clients. Often, structural violence is insidious and hidden within a workforce culture; as a form of violence it is subtle but harmful and damaging to those effected. Ho [21] argued that poverty is an example of structural violence at large. Those experiencing economically disadvantaged conditions suffer more, and yet this suffering goes largely unnoticed.

\section{Preparedness directives}

Discourses of preparedness or readiness are constructed as strategies to increase our ability to cope and adapt to disruption, while minimising damage and reducing insurance costs [14]. Discourses can be understood as sets of statements that governments and institutions use to direct knowledge, power and inform social practices. Once accepted, social discourses become taken-for-granted norms [42]. Preparedness practices, directed by governments and its agents, are social practices enacted through government-sanctioned texts that promote preparedness as a vital strategy to reduce risk from disasters or emergencies. Discourses of preparedness also rely on notions of resiliency as a way to promote preparedness and evaluate individual and community capacity to prepare and adapt to disasters [26]. However, disadvantaged groups can be overlooked or simply positioned as a symbolic reference in disaster preparedness policies and plans. Global research by UscherPines, Duggan, Garoon, Karron, and Faden [54] found that 37 pandemic preparedness plans from Europe, the Pacific Rim, Middle East, Africa and the Americas did not systematically identify disadvantaged groups. Less than 25 of these documents considered economically or socially disadvantaged groups.

In much the same way, two core Aotearoa/New Zealand's preparedness resources that provide a framework for people working in the emergency management sector pay little attention to the needs of disadvantaged groups and structural barriers to preparedness. For instance, the Ministry of Civil Defence and Emergency Management [36], a business unit for the Department of Prime Minister and Cabinet, distribute preparedness imperatives through its Civil Defence Emergency Management Plan [33]. Targeting central and local government, emergency services and non-government agencies, this plan outlines the roles, responsibilities and actions to take in an emergency. It argues for reducing hazard impacts to lessen the effects. The Aotearoa/New Zealand Ministry of Health National Health Emergency Plan [37] also warns citizens to prepare. Using an all-hazards approach to emergency management the plan aims to "reduce the likelihood of hazards, and to prepare for, respond to and recover from incidents and emergencies" (p. 6). It provides advice to the health and disability sector and welfare agencies, encouraging collaborative and multidisciplinary approaches to disasters and emergencies. The underlying assumptions behind these texts are the 4Rs of civil defence emergency management: readiness, reduction, response and recovery. Readiness and reduction largely involve preparedness activities, where risk is identified, analysed and mitigated to reduce harm [34]. These texts emphatically promote discourses of risk management and disaster preparedness, and rightly so. They are useful references for those working in the emergency management space. However, they do not discuss what might prevent people from being prepared or resource allocation. There are no directives for how emergency managers or planners could assist, or find the information to assist, communities to support people without the means to prepare, and they overlook alternative preparedness practices when traditional preparedness is unavailable, for whatever reason. Preparedness in developed countries, such as Aotearoa/New Zealand, is simply aimed at the individual level because it enables people to respond, adapt and recover [5] without being reliant on state support or intervention.

\subsection{Get ready: it's easy}

Preparedness discourses, produced through legislation and policy filter down and construct preparedness directives and practices. In Aotearoa/New Zealand the Ministry of Civil Defence and Emergency Management [36] has various disaster webpages on preparedness under the title How to Get Ready. These pages reinforce discourses of risk by warning people to prepare for hazards because of Aotearoa/New Zealand's isolated location and unique geographical climate. The website highlights how warning times are hazard related, for example weather-related or volcanic disasters provide some warning time, however an earthquake or tsunami can hit with little-to-no warning therefore preparedness plans are vital to survival. The webpages warn that all hazards have the potential to cause disruption, damage property and inflict death. There is advice on emergency survival items (such as having a torch, radio and non-perishable food), suggestions on educating children about hazard and disaster risks, and preparedness advice about storing baby food. There are lists of additional items to stock such as blankets, gas for cooking and a can opener for food. It suggests that people have a 'get away kit' in case they need to flee, or if away from home when an event hits. Ideally, to be sufficiently prepared, households should have an emergency kit at home and one in the car that contains similar items to those needed at home. There is a page 
specifically addressing how to make preparations for animals and livestock. The website has a section for people with disabilities. It mentions hearing, sight, physical, mobility, health and dietary requirements that may impact on the ability to cope. Overall the website, even though comprehensive, unfortunately neglects to mention what to do when emergency survival items are unaffordable, unavailable or unacceptable to particular groups. It fails to advise people on how to prepare when there is no ability to purchase preparedness products, such as food. It also ignores the specificity of gender, culture and linguistically diverse groups. Consequently, ontological security can be compromised when messages are difficult to read and communicate that potential harm can occur without preparedness. Structural violence is enacted because people are given risk scenarios and encouraged to prepare, but the institution disregards people's agency in preparing.

The Aotearoa/New Zealand Wellington Regional Emergency Management Office [56], a Civil Defence and Emergency Management service collaboration between nine councils in the greater Wellington region, declares getting prepared is easy. A booklet entitled It's Easy: Get Prepared for an Emergency [57] argues that preparedness actions help with "coping safely and comfortably following an emergency" (p. 0). The booklet outlines regional hazard risks, including earthquakes, tsunamis and floods, and lists important household preparedness activities, such as checking house foundations, securing hot water cylinders and household furniture to make homes safer. Practical tips include how to deal with overloaded phone lines and having an out-ofregion contact. People are encouraged to have an agreed meeting place and to discuss emergency planning with children. According to It's Easy [57], a disaster kit should include at least three days' supply of water. Three litres is just enough for survival; for hygiene and comfort, 201 per person per day are required [58]. The water should preferably be stored in recycled plastic bottles or shop-bought plastic containers to avoid contamination; it advertises the purchase of emergency water kits at $\$ 105$ each. Three days' worth of non-perishable food, an emergency toilet (you can use two buckets), hand sanitizer, one month's worth of medication, a battery powered or wind-up radio, torch, batteries, gloves, first-aid kit, cash, and supplies for children and animals as required. Similar to the Ministry of Civil Defence and Emergency Management webpages, there are no recommendations for what to do if you cannot afford food or a disaster kit, or do not have a car, or cellphone credit to make calls in an emergency setting. Whilst the advice provided is generally sound, the notion that it is 'easy' does not specifically accommoate those who cannot afford to action such messaging.

Becker et al. [5] found that many people believe that what they have in the home is enough for an emergency. This was supported following the Kaikoura 2016 earthquake, when the Wellington Regional Emergency Management Office [55] posted a document on Facebook that argued items in the home are sufficient for survival following a disaster. The post used a staff member's home as an exemplar for an emergency kit. This home included tinned food in the pantry (regularly restocked), bedding, camping gear, shed tools and a batteryoperated radio. The staff member had a 200-litre water tank in the yard and digital copies of photos and identification. They also owned a car. The text was an attempt to reassure people who believed getting ready was problematic due to the cost of maintaining a kit. However, assumptions were made that people had these items in their homes; it did not adequately acknowledge the plight of those who do not have, and cannot obtain, the recommended items and implicitly reinforced the importance of having a 200-litre water tank at a cost of $\$ 105$ per tank. Clearly, the Wellington Regional Emergency Management Office is committed to a community development model to addresses resilience for all communities, however it is vital that they acknowledge the social power relations that produce disaster vulnerability. Often when people are embedded in socio-economic conditions with complex needs, preparing for a disaster is not a priority need. That people are not directed on what to do without the suggested preparedness goods is concerning, especially when ontological insecurity could be triggered.
There is no denying that it is prudent to prepare, and certainly these texts provide useful advice on disaster survival strategies and tools. However, these texts target people who have Internet access, literacy skills, financial means and resources. They do not outline what people should do if they do not have the capability to make up a preparedness kit or ensure preparedness actions are complete, such as getting their landlord to assess house foundations or provide water tanks. Although the aforementioned institutions do great work and such initiatives must continue, public information sites should be supplemented with explicit acknowledgement of preparedness constraints and options for addressing these constraints. Without recognition of the social power relations that constrain people's lives, and without acknowledgment of the politics of socio-economic distribution, injustices occur.

\section{Research into preparedness practices}

The actions of government institutions are aligned within, and derived from, research activities. With the Aotearoa/New Zealand government's drive to get people to prepare, many researchers investigate what enables or constrains preparedness actions; how those actions matter, and to whom. For instance, research has demonstrated that the time, effort and cost of public education as a way to increase community preparedness is not working and the numbers of people who prepare, even when they know the risks, remains low [5,49]. However, as Becker et al. [5] argue most preparedness research is designed with an individualised lens that produces knowledge of a unitary subject, while positioning preparedness behaviour as an innate event $[10,16,43]$. For example, a report on Aotearoa/New Zealand preparedness strategies found that individual psychological processes, such as risk perception (will the event happen?), optimism bias (never going to happen to me) and response efficacy (lack of money, time and skills) are empirically founded explanations for preparedness behaviour [14]. Notwithstanding such findings producing knowledge that might enable movements towards preparedness action at an individual level, an individualistic focus fails to critique the socio-political contexts that produce structural violence and govern social and economic barriers to preparedness. According to Bolin [6], there is a long history of research that locates vulnerable groups with increased risk; however, such disparity, including the context in which vulnerable groups are embedded and how those contexts matter over time, is largely overlooked. There are, however, pockets of research that pay critical attention to the social structures that are implicated in barriers to preparedness (for example, see $[6,14,15,59])$. A critical research lens demonstrates that people with social power and privilege are more likely to prepare. People with higher incomes and more education, people who are parents and homeowners and have positive attachments to their communities are also more likely to engage in preparedness activities. Greater socioeconomic privilege and social capital can equate to increased preparedness behaviour because these people are able to take the necessary steps required to 'get ready' and be prepared [3].

Research demonstrates how disadvantaged groups unduly suffer due to governmental neglect of unique needs during disaster planning. For instance, the majority of the approximately 1600 people who died in Hurricane Katrina were poor, African American, or elderly. People died from floodwaters, starvation, dehydration or other abhorrent conditions while being stranded or residing in substandard emergency shelters with inadequate resources [25,38]. Bolin [6] identified class and ethnicity differences in effects and outcomes after disaster events. Similar case studies around the world demonstrate that disasters impact people unevenly and the need to ensure that disaster messaging is tailored to a range of social contexts. Economic and political marginalisation has been shown to have effects on some communities and layers of vulnerability contribute to outcomes. Researching and understanding the needs of disadvantaged people while situating that research in historical, geographical, social, political and economic spaces is required to enable inclusive preparedness practices for all. 
This involves the use of critical theoretical and methodological approaches that value cultural specificity, diversity and community participation that intersects with social-political and economic inequalities, hazards and risk reduction.

\section{Conclusion: reducing poverty and structural violence lessons risk}

It is a concern that most current preparedness messages generally neglect the poor living conditions of some Aotearoa/New Zealand families and highlights the imperative to make such messaging more inclusive. Boston [7] argues that a change in social values in Aotearoa/ New Zealand has seen a greater social acceptance of income inequality and relative poverty, which ultimately excludes particular groups from taking preparedness action. This acceptance of income divides alongside punitive welfare reforms reflects the consistent increase in poverty within our neoliberal context. The social problems that disasters accentuate have largely existed before the disaster occurred; disasters are extensions of hardships with people experiencing ongoing marginalisation through social processes including inadequate land use planning, poor building codes, poverty, substandard housing, lack of adequate health care and being ignored [16,54].

Although there have been some important changes to the emergency management reponses because of lessons learnt from previous disasters, Naser-Hall [38] argues for reducing poverty outside of an emergency, so that vulnerable people can address their needs prior to, and in anticipation of, a disaster occurring. For example, transport and communication should be accessible to all. Vulnerable populations should be involved in community disaster planning. Disaster planning should also use language that is instructional rather than aspirational, and include explicit provisions for assisting vulnerable people. In the same way, Ho [21] contends that we must examine how those in positions of power constrain agency, especially when fundamental, necessary human survival aids are inaccessible.

We argue that emergency management can be complicit, usually in tacit ways, in perpetuating structural violence towards the poor when their preparedness needs are articulated without an awareness of their everyday contexts and challenges. It is harmful to advocate preparedness without enabling economically disadvantaged groups which might want to prepare, but cannot for financial or social reasons, rather than the existence of complacency or choice. Ontological insecurity, the increase in anxiety when life and existence is experienced as fragile, can be generated for people who are unable to prepare. To understand how a disaster matters to economically and social vulnerable people, we need to understand the community before the event and to advocate for social change $[38,45]$.

There are now a number of key texts that aim to address disaster risk reduction and economic and social disparity. The United Nations Sendai Framework for Disaster Risk Reduction 2015-2030 [51] argues for all nations and community stakeholders to collaborate to achieve disaster risk reduction. Participation in strategies to reduce harm should not be discriminatory, but instead accessible to all who are affected by disasters, especially the economically disadvantaged. The new Sustainable Development Goals (SDG) [52,53] bring together economic, social and environmental features of sustainable development to argue for the importance of eradicating poverty to enable resilience and promote disaster risk reduction. According to the Aotearoa/New Zealand Ministry of Foreign Affairs and Trade [39], Aotearoa/New Zealand will contribute to the SDGs by aspiring to improve the economy, housing, living standards, health and education. There are also the other initiatives such as the Adaption Fund, which finances projects in countries particularly vulnerable to the climate change effects, which cause human disasters. The Adaption Fund serves the Paris Agreement (a global cause to combat climate change adaptation), by enhancing adaptive capacity, increasing resilience and decreasing vulnerability [1]. Vulnerable groups need to be considered in policies and practices, which represent a range of gender, ages, disability and cultural variables. The Aotearoa/New Zealand Human Rights Commission [24] also outlines steps to encourage those in a position of power and influence, and decision-makers to apply a human rights approach, by putting human rights principles at the centre of decision-making in civil emergencies, and more broadly when developing social policies. However, social policies do not always resolve, or translate to the deeply embedded social power relations that subjugate particular people and contribute to social vulnerability [29], and ontological insecurity for marginalised groups often long before a disaster occurs.

To resist inequalities, those in emergency management and allied fields cannot remain neutral, disengaged or impartial to the needs of marginalised groups [29]. Together we can work towards establishing community and government initiatives that focus on community development, building social capital and resources for the economically and socially disadvantaged. For example national and local governments could ensure that low-income housing is structurally safe and disaster-ready, or emergency planners could engage with vulnerable people to understand their needs and include them as valued stakeholders [38]. That the state enables preparedness to be attainable only for those in a position of privilege engenders structural violence against those without the means to prepare.

At a symposium address in June 2015, the then Minister of Civil Defence and Emergency Management, Nikki Kaye told senior government officials, non-government organisations, researchers, academics and emergency managers, that Aotearoa/New Zealand should attend to "reducing the underlying risk factors that create disasters ... in terms of economic and social capital. If we're serious about minimising New Zealand's future losses from disaster - protecting the lives and future prosperity of the country - our goal must be to manage risk, not manage disasters" [30, para. 4]. Emergency management stakeholders, communities and the people of Aotearoa/New Zealand (and indeed the world) must take up such a challenge and address the underlying sociopolitical conditions that produce increased risk for some; by attending to poverty, inequality, racism and discrimination, societies can attend to levels of risk by removing processes creating structural violence and enable people and communities to have a greater chance of ontological security both before, and after, a disaster event.

\section{References}

[1] A. Aitsi-Selmi, V. Murray, C. Wannous, C. Dickinson, D. Johnston, A. Kawasaki, T. Yeung, Reflections on a science and technology agenda for 21st century disaster risk reduction, Int. J. Disaster Risk Sci. 7 (1) (2016) 1-29, http://dx.doi.org/10. 1007/s13753-016-0081-x.

[2] D.P. Aldrich, Building Resilience: Social Capital in Post-disaster Recovery, The University of Chicago Press, Chicago, IL, 2012.

[3] L.R. Baker, L.A. Cormier, Disasters and Vulnerable Population: Evidence-based Practice for Helping Professions, Springer Publishing Company, New York, NY, 2015.

[4] U. Beck, Living in the world risk society, Econ. Soc. 35 (3) (2006) 329-345, http:// dx.doi.org/10.1080/03085140600844902.

[5] J.S. Becker, D. Paton, D.M. Johnston, K.R. Ronan, A model of household preparedness for earthquakes: how individuals make meaning of earthquake in formation and how this influences preparedness, Nat. Hazards 64 (2012) 107-137, http://dx.doi.org/10.1007/s11069-012-0238-x.

[6] B. Bolin, Race, class, ethnicity, and disaster vulnerability, in: H. Rodriguez, E.L. Quarantelli, R.R. Dynes (Eds.), Handbook of Disaster Research, Springer Science, New York, NY, 2007, pp. 113-129.

[7] J. Boston, Child poverty in New Zealand: why it matters and how it can be reduced, Educ. Philos. Theory 46 (9) (2014) 962-988, http://dx.doi.org/10.1080/ 00131857.2014.931002.

[8] L. Coombes, M. Morgan, South Pacific: tensions of space in our place, in: I. Parker (Ed.), Handbook of Critical Psychology, Routledge, New York, NY, 2015, pp. 444-453.

[9] D.P. Coppola, Introduction to International Disaster Management, 3rd ed. Butterworth-Heinemann, Boston, MA, 2015.

[10] M. Crossweller, Improving our capability to better plan for, respond to, and recover form severe-to-catastrophic level disasters, Aust. J. Emerg. Manag. 30 (4) (2015) $41-45$.

[11] L. Culver, Historicizing risk, in: Rachel Carson Centre (Ed.), Revisiting Risk Society: A Conversation with Ulrich Beck, Rachel Carson Centre Perspectives, 2011, pp. 7-10. 
[12] D. Denney, Risk and Society, Sage Publications, London, England, 2005.

[13] B. Eleven, EQC Pulls Traumatic Quake Ad, The Press, Christchurch, New Zealand, 2013 19, p. A1.

[14] P. Farmer, Pathologies of Power: Health, Human Rights, and the New War on the Poor, University of California Press, Berkeley, CA, 2003.

[15] K. Finnis. Creating a Resilient New Zealand: Can Public Education and Community Development Campaigns Create Prepared Communities? An Examination of Preparedness Motivation Strategies, 2004. Retrieved from 〈http://www. civildefence.govt.nz/assets/Uploads/publications/finnis-creating-a-resilient-newzealand.pdf> (Assessed 03 March 2016).

[16] H. Frumkins, Bumps on the road to preparedness, Am. J. Prev. Med. 40 (2) (2011) 272-273, http://dx.doi.org/10.1016/j.amepre.2010.11.001.

[17] J.C. Gaillard, Resilience of traditional societies in facing natural disasters, Disaster Prev. Manag.: Int. J. 16 (4) (2007) 522-544, http://dx.doi.org/10.1108/ 09653560710817011.

[18] J. Galtung, Violence, peace and peace research, J. Peace Res. 6 (3) (1969) 167-191.

[19] A. Giddens, Modernity and Self-identity: Self and Society in the Late Modern Age, Stanford University Press, Stanford, CA, 1991.

[20] R.L. Hawkins, K. Maurer, "You fix my community, you have fixed my life": the disruption and rebuilding of ontological security in New Orleans, Disasters 35 (1) (2011) 143-159, http://dx.doi.org/10.1111/j.03613666.2010.01197.x.

[21] K. Ho, Structural violence as a human rights violation, Essex Hum. Rights Rev. 4 (2) (2007) 1-17.

[22] D. Hodgetts, K. Chamberlain, S. Groot, Y. Tankel, Urban poverty, structural violence and welfare provision for 100 families in Auckland, Urban Stud. 51 (10) (2014) 2036-2051, http://dx.doi.org/10.1177/0042098013505885.

[23] S. Hoffman, Preparing for Disaster: Protecting the Most Vulnerable in Emergencies, University of California, Davis, 2009 Retrieved from 〈https://lawreview.law. ucdavis.edu/issues/42/5/articles/42-5_Hoffman.pdf $\rangle$.

[24] Human Rights Commission Te Kāhui Tika Tangata, s. Monitoring Human Rights in the Canterbury Earthquake Recovery. A Report by the Human Rights Commission, 2013. Retrieved from 〈https://www.hrc.co.nz/files/6414/2428/1599/HRCEarthquake-Report-2013-final-for-web.pdf .

[25] C.C. Jaeger, T. Webler, E.A. Rosa, O. Renn, Risk, Uncertainty And Rational Action, Earthscan, New York, NY, 2001.

[26] A.H. Kwok, E.E.H. Doyle, J.S. Becker, D. Johnston, D. Paton, What is (social resilience'? Perspectives of disaster researchers, emergency management practitioners, and policymakers in New Zealand, Int. J. Disaster Risk Reduct. 19 (2016) 197-211, http://dx.doi.org/10.1016/j.ijdrr.2016.08.013.

[27] U. Lübken, On the role of natural hazards and catastrophes, in: Rachel Carson Centre (Ed.), Revisiting Risk Society: A Conversation with Ulrich Beck, Rachel Carson Centre Perspectives, 2011, pp. 10-12.

[28] F. Luna, Elucidating the concept of vulnerability: layers not labels, Int. J. Fem. Approaches Bioeth. 1 (2) (2009) 121-139.

[29] V. Lyon-Callo, Inequality, Poverty, and Neoliberal Governance, Broadview Press, Ontario, Canada, 2004.

[30] A. McElroy, New Zealand Strong on Sendai Framework, 2015. Retrieved from 〈https://www.unisdr.org/archive/44892〉.

[31] I. McLean, D. Oughton, S. Ellis, B. Wakelin, C.B. Rubin. Review of the Civil Defence Emergency Management Response to the 22 February Christchurch Earthquake, 2012. Retrieved from 〈http://www.civildefence.govt.nz/resources/review-of-thecivil-defence-emergency-management-response-to-the-22-february-christchurchearthquake/ $>$.

[32] R. Mechler, Macroeconomic Impacts of Natural Disasters, World Bank, 2003, p. 2003

[33] Ministry of Civil Defence \& Emergency Management, Business Plan: 2015-2019, Author, Wellington, NZ, 2015.

[34] Ministry of Civil Defence \& Emergency Management, Guide to the National Civil Defence Emergency Management Plan 2015, Author, Wellington, NZ, 2015.

[36] Ministry of Civil Defence \& Emergency Management. How to Get Ready, 2016. Retrieved from 〈http://www.getthru.govt.nz/how-to-get-ready $\rangle$.
[37] Ministry of Health. National Health Emergency Plan: A Framework for the Health and Disability Sector, 2015. Retrieved from 〈https://www.health.govt.nz/ publication/national-health-emergency-plan-framework-health-and-disabilitysector $>$.

[38] E. Naser-Hall, The disposable class: ensuring poverty consciousness in natural disaster preparedness, DePaul J. Soc. Justice 7 (1) (2013) 55-86.

[39] New Zealand Foreign Affairs \& Trade. Sustainable Development Goals, 2017. Retrieved from 〈https://www.mfat.govt.nz/en/peace-rights-and-security/workwith-the-un-and-other-partners/new-zealand-and-the-sustainable-developmentgoals-sdgs $/>$.

[40] New Zealand Police Nga Pirihimana o Aotearoa, Christchurch Earthquake: List of Deceased, 2012, 21 August 2016. Retrieved from 〈http://www.police.govt.nz/ major-events/previous/christchurch-earthquake $\rangle$.

[41] I. Noy, The macroeconomic consequences of disasters, J. Dev. Econ. 22 (2) (2009) 221-231, http://dx.doi.org/10.1016/j.jdeveco.2008.02.005.

[42] I. Parker, Critical Discursive Psychology, Palgrave MacMillan, New York, NY, 2002.

[43] D. Paton, D. Johnston, Disasters and communities: vulnerability, resilience and preparedness, Disaster Prev. Manag.: Int. J. 10 (4) (2001) 270-277.

[44] B. Perry, Household Incomes in New Zealand: Trends in Indicators of Inequality and Hardship 1982 to 2014, Ministry of Social Development, Wellington, NZ, 2015.

[45] H. Rodriguez, E.L. Quarantelli, R.R. Dynes, Editor's Introduction, in: H. Rodriguez, E.L. Quarantelli, R.R. Dynes (Eds.), Handbook of Disaster Research, Springer, New York, NY, 2007.

[46] P. Rohleder, Critical Issues in Clinical and Health Psychology [Electronic Resource], SAGE, London, England, 2012.

[47] J. Simpson, M. Duncanson, G. Oben, A. Wicken, S. Gallagher, Child Poverty Monitor Technical Report, New Zealand Child and Youth Epidemiology Service, University of Otago, Dunedin, New Zealand, 2011.

[48] J. Simpson, M. Duncanson, G. Oben, A. Wicken, M. Pierson, Child Poverty Monitor 2015 Technical Report, NZ Child and Youth Epidemiology Service, University of Otago, Dunedin, NZ, 2015.

[49] Statistics New Zealand, How Prepared are New Zealanders for a Natural Disaster? Results from the 2010 General Social Survey, Author, Wellington, NZ, 2012.

[50] K. Tierney, The Social Roots of Risk: Producing Disasters, Promoting Silence, Stanford University Press, Stanford, CA, 2014.

[51] United Nations, Sendai Framework for Disaster Risk Reduction 2015-2030, United Nation's International Strategy for Disaster Reduction, Sendai, Japan, 2015.

[52] United Nations. Sustainable Development Knowledge Platform: Sustainable Development Goals, 2017. Retrieved from 〈https://sustainabledevelopment.un. org/sdgs $>$.

[53] United Nations Office for Disaster Risk Reduction. Implementing the Sendai Framework to Achieve the Sustainable Development Goals, 2016. Retrieved from $\langle$ https://www.unisdr.org/we/inform/publications/50438〉.

[54] L. Uscher-Pines, P.S. Duggan, J.P. Garoon, R.A. Karron, R.R. Faden, Planning for an Influenza Pandemic: Social Justice and Disadvantaged Groups Hastings Center Report, 37 (2007), pp. 32-39.

[55] Wellington Regional Emergency Management Office. Breaking Down the Barriers Emergency Kits, 2016. Retrieved from 〈https://www.facebook.com/notes/ wellington-region-emergency-management-office-wremonz/breaking-down-thebarriers-emergency-kits/1416852378344057> (Assessed 03 March 2016).

[56] Wellington Regional Emergency Management Office, Wellington Regional Emergency Management Office, 2017. Retrieved from 〈http://wremo.nz/〉.

[57] Wellington Regional Emergency Management Office, It's Easy: Get Prepared for an Emergency. Author, Wellington, NZ, n.d.b.

[58] Wellington Water,Resilience - Drinking Water and Wastewater, 2017. Retrieved from 〈https://wellingtonwater.co.nz/your-water/resilience/〉 (Accessed 09 October 2016)

[59] B. Wisner, P. Blaikie, T. Cannon, I. Davis, At Risk: Natural Hazards, People's Vulnerability and Disasters, Routledge, New York, NY, 2004.

[60] M.J. Zakour, D.F. Gillespie, Community Disaster Vulnerability: Theory, Research, and Practice, Springer, New York, NY, 2013. 